\title{
Rethinking the Harmonious Family: Processes of Social Organization in a Korean Corporation
}

\author{
Charlotte JonAsson AND JAKOB LAURING
}

\begin{abstract}
Social harmony and stability have been described as almost inborn aspects of Korean corporations. After the East Asian economic crisis of 1997, however, most Korean organizations faced new demands for increased productivity and competitiveness. The fragile balance between social harmony and individual competition led, in some Korean corporations, to social negotiation and struggles to define the aim and character of the collective effort. By describing the subsequent social dynamics of a Korean bank corporation, this article aims to show how the perception of group harmony as a stable entity in East Asian organizations is too static a concept for analysing the social organization. Rather, the dynamics of the continuous production and reproduction of social structures have to be taken into account in order to understand working life in Korean organizations.
\end{abstract}

\section{Introduction}

Asian corporate culture is often associated in a positive way with productivity and efficiency (Deal and Kennedy 1983; Ungeson et al. 1999). The prevalent argument is that the Asian style of organizational culture combines collectivity and team spirit with hard work, precision and dedication (Vogel 1979; Ouchi 1982). Although specific cultural traits have been identified in Korea's search for corporate excellence, analysis of the role of the social organization in Asian corporate life has often proved rather superficial. This is because of studies have tended to postulate a direct relation between, on the one hand, a harmonious family orientation to working life and, on the other, positive financial results (Chang 1999; Kim 1999; Peters and Waterman 2004).

During the 1980s, economic growth in a number of East Asian countries surpassed even that of the US (Pascale and Athos 1981). In South Korea, the annual economic growth rate rose to 11 percent at the beginning of the decade, the highest ever recorded globally. This economic success can be ascribed to a number of factors, inter alia: US support 
for the reconstruction of South Korea after the civil war (1950-54); the opportunity to emulate the success of its neighbour, Japan; the special relationship in South Korea between corporations and the state, whereby the great conglomerates, the so-called 'chaebols', were favoured by the national bank, and where politics and economics were less divided compared to most Western countries (McMichael 2002; Rhee and Chang 2002; Rowler, Sohn and Bae 2002). Economists, however, have linked the success of Korea not only to macro-economics and societal structures, but also to the productive potential of the companies themselves (Lee 1998; Ungeson et al. 1999).

\section{The Profitable Harmony of Asian Organizations}

Among cultural researchers, especially within the functionalist tradition, there has been a consensus that the explanation for South Korea's economic success is to be found in the human and social factors shaping organizational life (Hofstede 1991). As Hofstede and Bond (1988: 106) write: 'For the real explanation, we must turn to the domain of culture.' Hence, it was deemed that the national cultural traits and the social organization of Korean workers were contributing to the fertile conditions on which the financial success had been achieved (Chang 1999; Kim 1999). On the basis of this, it was argued that an almost 'natural' positive connection exists between organizational coherence, social harmony and financial achievements (Tsukaguchi-le Grand 1991; Rowler, Sohn and Bae 2002). Social harmony is here to be understood as mutually accepted and maintained, conflict-free social relations (Hall and Ames 1987; Song and Meek 1998).

The organization of Korean companies is frequently linked to Confucian principles (Oh and Kim 2002; Gudykunst 2004). Indeed, according to a number of cultural writers, the Korean national culture is particularly influenced by Confucian tenets (Chang 1999; Ungeson et al. 1999). In Confucianism, the family is perceived to be the entity towards which group members feel the greatest responsibility and loyalty. Companies have appropriated this familial analogy, to the extent that employees are described as members of the greater corporate family (Kim 1999; Jandt 2001). As Hofstede (1991: 51) puts it: '[Korea is a society] in which people from birth onwards are integrated into strong, cohesive in-groups'. This argument was based on Hofstede's fifth dimension, namely long-term versus short-term life orientation, which in earlier articles was dubbed 'Confucian dynamism' (Hofstede 1991; Hofstede and Bond 1988). 
However, the scientific basis for this premise has been criticized amidst calls for a more nuanced philosophical understanding of the cultural dimension itself, and for clarification of the precise link between Confucian cultural heritage and economic success (Fang 2003). Nonetheless, many accounts of East Asian cultural values have been linked to Hofstede's findings. As with family, East Asian companies tend to be organized in a hierarchical stratification as the foundation of the social order. It is thus argued that the vertical relationship between superiors and subordinates guides all human interaction in Korea and that social coherence and harmony are dependent on the observance of these relationships (Kim et al. 2002).

A related aspect of Confucianism is that of trust between superiors and subordinates. According to this viewpoint, when acting within the hierarchical framework, Koreans have an intuitive feeling for social balance and harmony (Gudykunst 2004). The Confucian ideology thus supports the maintenance of harmonious relationships. Furthermore, the expressed empathy between group members is considered necessary in order to build satisfactory social interactions (Hahm 1986; Chang 1999). In other words, social harmony among employees is crucial for maintaining smooth relations in the hierarchically structured Korean organizations. People who bring feelings of social harmony and stability into an organization tend to be valued more highly than people who can perform but who fail to gain the loyalty and friendship of superiors, peers and subordinates (Chang 1999; Oh and Kim 2002). Upholding family relations within the company also means that superiors are obliged to root out any feelings of discontent within groups of subordinates and try to solve the problem (Song and Meek 1998). The harmonious social unit thus becomes a mutual project between the different group members with the aim of achieving sustainable interdependence through social reciprocity (Hall and Ames 1987; Ames 1993).

Song and Meek (1998) argue that long-term group harmony has traditionally been viewed as essential for the survival and progress of Korean organizations (e.g. Chang 1999; Ungeson et al. 1999). They cite a wellknown popular proverb: 'Only if a family works together in harmony can it succeed'. The emphasis on maintaining social harmony stands in contrast to more individualistic and performance-oriented Western ideologies such as liberalism (Chung and Jang 1997). The competitive employee who cannot subordinate his or her personal aims to the collective cause is not well accepted in Korea because of the damage this can cause to group harmony. Hence, individual actions are to a large extent 
evaluated by their contribution to the interests of the group and to group harmony (Triandis 1995; Chang 1999). Group affinities and a collectivist view on performance are not considered antithetical to productivity. As stated by Ungeson et al. (1999: 241): 'A Korean employee's work effort is primarily group oriented. Hard work is done so that the group - that is, the company - will succeed.' Theories of Korean corporate culture thereby, in a causal and linear way, describe the correlation between a harmoniously integrated form of social organization and economic success. The positive link between Asian culture and productivity, however, was further challenged by events during the economic crisis of 1997. ${ }^{1}$

\section{Asian Culture and the Economic Crisis}

After the Asian economic crisis of the late 1990s, the organizational structures of the great chaebol companies and close familial relations between corporations, banks and in many cases the government, came to be challenged - especially by the International Monetary Foundation (IMF) (Lee 1998; Lee 2003). On a general level, there were demands for greater flexibility and transparency both in the managerial structures and in terms of employment relations. It was argued that new values of individuality and equality and a general dissolution of the familylike social structure could lead to enhanced corporate transparency, improved competition and enhanced conditions of employment, thus freeing employees from hierarchical obligations. This was, from an Asian point of view, seen as Western management ideology and as a precondition exacted for the IMF loans granted to East Asian countries like South Korea (Patterson 2002; Rhee and Chang 2002; Lee 2003).

In the years following the economic crisis, many commentators changed their appraisal of the Korean group-oriented culture. They started to criticize it for hindering healthy competition as well as preventing equal opportunities in the workplace (Chang 1999; Ungeson et al. 1999; Patterson 2002; Rhee and Chang 2002; Rowler, Sohn and Bae 2002). ${ }^{2}$ Korean corporate culture was described as making employees negatively dependent on their superiors. In addition, it was now stated that the Korean culture had the disadvantage of leading to inefficiency and 'group think' (Janis 1982; King and Anderson 1990; Adler 1997).

Given the discrepancies between the two different interpretations of the role of Asian corporate culture in relation to corporate performance, the applied functionalist theories of culture seem inadequate to account for the social organization of Korean companies. The present authors 
will argue in this article that the outline of a stable and predictable relationship between Asian culture and productivity - whether positive or negative - is highly problematic. Furthermore, the harmony of social relations in Korean organizations should not be taken for granted or considered a static, inborn trait. On the contrary, the character of social relations should be considered as subject to continuous renegotiation and as embedded in daily interaction. This, in turn, determines the meaning of the ideal - the organization as a harmonious family.

Hence, to provide an alternative and more dynamic perspective on the interrelation between culture and productivity, an anthropological approach has been selected by the present authors. The aim of this article is thus to outline the social dynamics of a Korean organization in a process of transition between the traditional Asian values of group harmony and the newly introduced Western values of individual competition.

\section{The Dynamics of Social Organization}

In this article, a process-oriented anthropological approach has been applied to reach a dynamic perspective on the creation and maintenance of culture as social structure (Bourdieu 1977; Bourdieu 1990). In this regard, the generative model developed by Barth (1966) is useful for its description of the production and reproduction of cultural patterns, and can be applied to Korean corporate organizations. This anthropological approach stems from an analysis of the processes of action rather than from the structures of actions that usually characterize the functionalist approach to culture (Deal and Kennedy 1983; Hofstede 1991; Peters and Waterman 2004). In the generative model, an investigation into the creation, maintenance and distribution of both cultural forms and structures is central for the understanding of social organization (Barth 1993).

Social processes, according to Barth (1966), are developed through symbolic and economic transactions between individuals - including different forms of social exchange, boundary spanning and categorization. Individuals engage in an ongoing number of negotiations in an attempt to maximize the resources and recognition available to them (Bourdieu 1990). In this way, social structure is generated over time on the basis of strategic choices made in the course of interaction.

When guidelines for action are continually subject to renegotiation, structures or patterns of action should only be conceived as momentary products of the social processes. Social structure, in other words, is not a 
constant or unchanging concept, independent of interaction and transaction. Even when structures in time are stabilized - or reified (Herzfeld 2005) - in the individual application of collective representations as socalled legitimizing prophecies (Weick 1979; Weick 1993), they should not be considered immutable entities. Instead they are reproduced and modified over time when applied strategically by individuals. As Barth puts it:

I advise that we should try seeking our insights in wider and opener fields of social processes. Social activity is an ongoing activity of world-making; the forms of culture are not best explained by abstracting their general principle but by asking what each particular pattern may be evidence of. We must ask just what kind of consistency we find in each particular pattern and why this form develops just here. (Barth 1989: 32)

Social structures, according to Barth (1966), should be regarded as continually in the process of being made and maintained. This makes his model convenient for our analysis of the social processes involved in creating organizational order. A supplementary anthropological approach to the study of change in a social context is offered by Moore $(1978 ; 1994)$. She introduces the two concepts of 'processes of regularization' and 'processes of situational adjustment' which can be used to explain the interpretive social processes through which both social stability (maintained structure) and social change (transformational processes) can be achieved. Processes of regularization are to be seen as social processes with the purpose of producing and reproducing a social order, thereby leading to continuity and predictability. Processes of situational adjustment, on the other hand, create changes in the social order, leading to ambiguity and reinterpretation. The central argument is that: 'every interaction contains within it elements of the regular and elements of the indeterminate and both are "used" by individuals' (Moore 1978: 40). The argument is based on the assumption that individuals attempt to regularize social life by the imposition of different ideologies, norms and rules, but that every attempt of this sort will at the same time be challenged by ambiguity, manipulation and inconsistency (Moore 1978). The issue of social coherence, harmony and stability is thereby framed by the fact that a given social order can never fully be established.

By using the ideas of Barth (1966) and Moore (1978), we can view organizational interactions and transactions as capable of leading to processes of both regularization and situational adjustments. This article will investigate how the upholding of internal group harmony and solidarity in practice can be related to an ongoing negotiation of 
value and practices of acquiring resources and recognition (Bourdieu 2004). Taking as our starting point this dynamic view on culture as the momentary product of social processes, we set out to describe how the dynamics of social organization in a Korean organization are framed by corporate structural transformation. Due to the embedded complexity of the field research, the investigation focuses on ethnographic fieldwork conducted in close relation to the actual setting.

\section{Methodology}

To understand and analyse the social organization of Korean corporations, it is necessary to carry out an in-depth and on-site investigations (Geertz 1973). In this case, the methodology of ethnographic fieldwork was applied during a three-month period by one of the authors using participant observation and semi-structured interviews as data collection tools. The company selected was a Korean credit card company which we have named AC Card Company. Observations were carried out through daily presence in the organization and during social gatherings after working hours.

A primary aim of the participant observations was to reveal hidden structures and themes to be discussed and documented later through interviews (Bernard 1995; Dewalt et al. 1998). Thus participant observation becomes crucial to the understanding of implicit interaction patterns (Edgren 1990). Subsequent to the observations done in the field, 42 interviews were conducted with Korean employees and managers - in a combination of both Korean and English (Jonasson and Lauring 2005). Generally, the interviews were kept as an open dialogue between the researcher and the informant. The informants were asked to describe events and situations relevant to the social organization of their department (Bernard 1995).

The research project was carried out according to hermeneutical anthropological principles, which can be described as open and circular. In this approach, new questions and themes are continually integrated in the data collection tools such as interview guides and observation schemes. The investigation is thereby initiated exploratively, focusing increasingly on central themes observed or mentioned by informants. In this way, the technique combines openness towards the different informants' view with a systematic scientific approach (Spradley 1980; Marcus 1995). 
Data analysis was intertwined with data collection, and the categorization of statements and observations was initiated during the practical part of the fieldwork (Spradley 1980; Miles and Huberman 1994). By conducting the analysis in tandem with the data generation, it was possible to incorporate the evolving themes and subsequent ideas in the continuously changing interview guide. During the analysis, the statements and observations were organized thematically in indexes and taxonomy trees with subcategories (Spradley 1980; Bernard 1995).

The Korean corporation AC Card is an interesting case for demonstrating the social dynamics of the Asian workplace in a situation of transformation. At the time of the research, the local Shinchon branch, where the fieldwork was conducted, had been characterized as the best-run branch in the entire corporation. The AC Card Company - and especially the Shinchon branch - represented the managerial and organizational style that many Korean companies still strive to attain.

AC Card Company was a comparatively large corporation with around 2,000 employees, divided into the Headquarters (HQ) and 11 branches. Shinchon branch had 35 employees divided into three teams on three levels. Most of the employees were relatively young - between 20 and 30 years old (Jonasson and Lauring 2005).

The advantage of conducting ethnographical fieldwork is that it gives the researcher a deeper understanding of the setting, thereby allowing the results to be presented as 'thick description' (Geertz 1973). This supplies the reader with multidimensional information, cross-relating different sources and perspectives within the discussion of the central themes. This approach is particularly valuable in the study of hidden or sensitive issues such as the social organization of power relations. The limitations of this approach relate to the difficulty of generalizing the results to other business contexts. However, through the ethnographic approach, the researcher can obtain information that may provide a deeper understanding of human behaviour in a specific context. The learning potential thus lies in understanding the processes of human interaction at a deeper level than is generally achieved in organization studies (Deal and Kennedy 1983; Peters and Waterman 2004). It has further been argued by Flyvbjerg (2001) that generalization is possible on the basis of case studies, creating a so-called 'phronesis' or practical knowledge, in as much as this knowledge represents a context-based foundation for further theorizing. 


\section{Korean Management in Times of Transition}

After the Asian economic crisis of 1997, AC Card Company was competing vigorously with other banking companies. The main focus during the millennium shift was to change the company's formal management and employment strategies. It was argued by AC Card's top management that there was a need for a new organizational design to improve productivity and transparency. As one of the HQ managers put it, the target was to develop a managerial style 'where old-time family and friendship-like alliances are replaced by rational leadership and individual performance'. The strategy of replacing the family-oriented ideology with individualistic procedures, was not, however, supported unanimously by others at HQ. Subsequently, the new motto or sahoon was formulated as: 'by oneself, progress, all together' (Soesoero saeropkae takachi). ${ }^{3}$ It expressed a management ideology of a balanced and sustainable relation between individual competition and collective harmony. In Korea, employees are, ideally, supposed to be influenced by a deeper understanding of the sahoon to the point where their attitudes and personal values directly match the ideals of the corporation (Bar-Tal 1990). ${ }^{4}$ Generally, it can be said that corporate mottos aim to inspire employees to give of their best and to evoke a sense of corporate pride. Further, the sahoon is also meant to represent the firm's core values - or, at least, the core values it would like to be known for externally (Lee 1989).

The formal statements of AC Card Company thus expressed an ideal balance between the older harmonious family values and the newly introduced individualized, competitive style of management. The outcome, however, was a general feeling of instability and insecurity experienced by many of the employees. But as will be shown, the new management ideologies were also subject to different situational adjustments and a strategic utilization of ideologies; moreover social directives were developed at the local level in the pursuit of individual and group-based goals (Barth 1966; Moore 1978).

By increasing the focus on individual achievement, the company generally aimed to improve performance. This argument led to the implementation of new formal systems as 'tools' for management changes, in an effort to enhance individuality and productivity in a Western fashion. An example of this can be identified in the objective of replacing the 'old-time' hierarchical stratification with a flatter, more egalitarian organizational structure which left only three position levels in the branches: manager, team leader and team worker. This was 
seen as a radical empowerment of the regular employee's position, as articulated by one team leader:

So before, it was unthinkable, that work just went through the hands of maybe two people but nowadays it is the way we do it. The team worker may go to his team leader but not to everybody because he himself can make some decisions.

One favoured aspect of the new company policies was the implementation of a five-day working week, as opposed to a previous lack of regulation in this area. The shorter working week was often mentioned when describing the improved working conditions ushered in by the new management style. Employees now were to be measured on their actual performance rather on than the hours spent on the job. To this end, a Management By Objectives (MBO) system was introduced in order to better monitor the performance and business results of each branch, each team and each individual. Most upper-level informants agreed that both managers and subordinates were inspired by these new means of increasing decentralization, transparency and more equal opportunities for advancement.

About the culture (munhwa), well, compared to other companies I think the 'regulars' (ilbanchik) like that it is more rational (hapnichokoero) here. They like the rational based culture here. The 'knowledge system' as well as the $\mathrm{MBO}$ are based on giving work a lot of thought and also between them and the people below there is a freedom to communicate and help each other. In that way there is a much more easy and open way of communicating here and I think that is also what they like. (General Manager)

Yet this freedom to communicate was not acknowledged by all team members. Indeed, one team member when describing the weekly team meetings, imitated the team leader pointing a finger and saying 'Do this and do that' (hae hae).

Another result of the new $\mathrm{MBO}$ system was the creation of a group of temporary workers and contractors with very insecure employment conditions. This has been the general labour market development in Korea within recent years, whereby a more flexible workforce is deemed most conducive to the survival and competitiveness of Korean corporations (Lee 2003). Also in AC Card Company, the group of temporary workers were seen by the local management as a means to improve the flexibility of the local branch. Subsequently, the systems were interpreted so that the temporary staff could be utilized to create the needed MBO results. This was mainly achieved by forming local 'notions' (Holy and Stuchlik 1983; Barth 1989; Barth 1993) of collectivity and cooperation 
that could be deemed contradictory to the new company policy of individual accountability. The individual results measured by the MBO were 'officialized' ${ }^{15}$ as a shared overall project (Bourdieu 1977). This meant that the temporary employees were included in the joint efforts to improve $\mathrm{MBO}$ measurements - despite the fact that they, due to their short-term contracts, had no possibility of benefiting career-wise from the $\mathrm{MBO}$ results. This was much criticized by the contractors, yet only during informal talks:

I am not really part of it [MBO]; it doesn't really affect me and my salary. I am only a 'temp'. But it does matter to our team leader because the MBO decides how he will be rewarded. So for 'the regulars', the MBO is important and they also want to make it important for us, but [our role] is more support for the others, rather than the $\mathrm{MBO}$ having a direct effect. But they want us to improve the $\mathrm{MBO}$ for them. We all just work hard to help others to get promoted. In general here in the branch it is not [a matter of the] individual.

According to this local interpretation of the new management systems (by oneself, progress, all together), collectivity was outlined as hierarchical managerial structures; this was also the case when evaluating individual staff members. An example of this was the yearly election within the branch of the co-workers who were recommended for promotion and job-rotation. According to the new corporate ideologies of transparency and equal opportunities, this ought to have been decided democratically, based on an evaluation of each individual's MBO results. This was not, however, always the case in practice. Rather, attention was more focused on the established hierarchical structures and collective harmony criteria.

I think there are two factors [for promotion]. First, there is the result or the $\mathrm{MBO}$ and second, people have to like them and they have to be considered very harmonious and have nice personalities. That is actually most important. So if you prove to be nice and make good relations with the top people, then you can get promoted. (Team Worker)

As mentioned by some of the employees, the new 'Western' management style was perceived as having a significant - and negative - impact on social relations in the organization. The tangible result was a growing turnover not only among temps and short-term contractors, but also among the 'regulars' (ilbanchik) searching for new employment. Many informants mentioned the extensive pressure on the individual to deliver good results - and in many cases without any direct benefits for oneself - as the primary reason for increased staff turnover. The 
high rate of employees leaving the company, plus the time and effort needed to integrate new staff in the department, were cited by some, even team leaders, as destroying morale in the group.

I do not think that the Western style like the MBO is always that good. You know, it is very good for getting results. But it can ruin the atmosphere (punhigi) because people are always fighting and are very selfish. They do not feel that they have to help each other and communicate. And as I said, I think that atmosphere is most important - then afterwards come results. (Team Leader)

As described above, some of the contradictions between economic and social incentives stemmed from the team leaders' local interpretation and 'officialization' of different managerial ideologies. In this process, the local managers argued for the integration on the one hand of both new management ideas of individuality and transparency and, on the other, of the traditional values of family and hierarchy.

\section{Creating a Harmonious Family: Processes of Regularization}

The upholding of the hierarchical relations, despite corporate guidelines, was legitimized by management as a concern for social well-being, harmony and coherence in the local branch. The Shinchon management explicitly described it as a form of local mutual responsibility, as opposed to the general harsh individual competition promoted by HQ. This created a polarization between the two managerial discourses: one was termed the 'American way' by the employees and the other was termed the 'Korean way'. In this regard it was claimed by the local management that a constructive balance between the two ideologies could be achieved by developing an organizational structure mirroring that of a 'harmonious family'. As stated by one of the team leaders:

They stay together and I find it is good because through their time together they will see each other more and more like a family. And also because nowadays, there is so much competition, so it will help to be like a harmonious family (hwahapeun kachogi) - to overcome it. But this said, you know it is mostly only in mind, not in action. But here I think people really like to be together and do show responsibility for one another.

Through loyalty and mutual solidarity within the 'harmonious family', the destructive polarization between individuality and collectivity was supposedly reconciled. This effort by the local management to cre- 
ate a family ideology may be conceived as a process of regularization (Moore 1978), whereby they tried to stabilize an unstable social situation by introducing a local idea of mutual loyalty and accountability in the production of a new social order - the 'Korean way'. This was done by social gatherings after hours, with the official aim of fostering social awareness, harmony and responsibility among group members - also among the temporary workers who in many cases were excluded from benefits such as promotion and bonus systems.

One way in which these gatherings aimed to boost social integration was through the use of drinking games. This was one strategy developed by managers to initiate newcomers within their working teams. ${ }^{6}$ To give an example: a newly employed contractor was encouraged, by his team leader, to compete with his older team member (sonbae) at a beerdrinking competition after work. When he tried to avoid this situation, his manager replied: 'You will drink this in respect of your sonbae'. He explained to the researcher: 'This will teach him that he must do what his sonbae tells him'. Later he explained that he valued these social gatherings as a way of fostering team loyalty and a feeling of group integration, despite the high turnover rates among contractors and dispatchers: 'I think it is important that my workers have a good time together after hours. Then they will not be sorry to work so hard.'

This example reveals why these social gatherings were in fact mandatory and an extended part of the employees' work description. Each day various efforts were made to promote social 'family' oriented initiation and integration rituals (Turner 1969; van Gennep 1990), whereby the demarcation line between work and social life became blurred. This was with the intention of making the co-workers, including temporary workers, devote even more time to the company - thus working and contributing to the financial results of the branch. The managerial strategy of incorporating extensive social events within the working life of the branch had a positive effect on the creation of a family orientation within the department simply because people had no time left for social relations outside work.

Here, we cannot just go home after work, we have to go out to drink and eat or work overtime. We spend a lot of time in the company. We don't have time to meet our old friends from university and we lose touch with them once we join a company. This is difficult, but we don't have any interest in those things any more - just in the company. I like that attachment (chipchak) to the company. 
In this way, the local interpretation of the overall policy of productivity optimization was considered by some to be the responsible and harmonious resolution of the difficulties of competition, which the new organizational structure and managerial style promoted by HQ had introduced. Yet, it was a harmonious social order, which had to be produced, regulated and preserved continuously.

We must be good at cooperation, and to do that we must preserve the harmony within the group. If people do not know each other well and new people often come in, then the harmony will be destroyed and that can show up in the results. (General Manager)

\section{Individual Strategies: \\ Processes of Situational Adjustment}

As can be seen above, no absolute consensus existed on the precise meaning of the newly developed managerial ideals. And the inherent contradiction between individuality and collectivity, to a large extent, gave rise to conflicts within the department. Subsequently, groups and individuals strategically employed the ambiguity of the concepts in the struggle for resources and recognition, such as promotion and bonus benefits (Bourdieu 1990). Instead of underscoring the presumed responsibility for their subordinate co-workers and 'family', management utilized the ideology of the harmonious family and devotion to work to enhance their own individual promotion rather than to support the group's cohesion, harmony and welfare.

The departmental managers defined the ideals in such a way as to keep themselves positioned at the top of the hierarchy. They therefore had a reason for initiating the 'family' strategies to achieve productivity, as these aimed to secure their own promotion, founded on their ability to deliver results. Their actions were much criticized, albeit not in public, by the team workers:

You know team leader Park doesn't really care about his workers and I think that the atmosphere punhigi in our team is getting worse and worse. But he just cares about his own [MBO] result. You know he wants to go to another branch and get promoted to GM. He also doesn't care about how it will affect the team if he gets promoted. Because, you see, he has now actually 'milked' the area for money, so it will be very hard for the next team leader to achieve good results. 
This approach can be interpreted as the situational adjustment of the two different ideologies (the American way and the Korean way) to fit the manager's own needs in order to cope with the new demands from HQ. At the same time, efforts were made to produce and reproduce a social order, in addition to undertaking efforts to mend 'cracks and holes' within this picture of a harmonious family. Both processes were applied more or less strategically to serve the manager's own needs (Moore 1978). Herein also lay a power aspect. Although it was possible for all co-workers to interpret different ideologies, only some of the managers had the power to use these interpretations more strategically. However, it was a general opinion that all co-workers - including the better-positioned team leaders - were under pressure to deliver good business results and thereby live up to the standards demanded by HQ.

The case study has shown that the strategy of maintaining a harmonious and loyal workforce is not easily achievable. For example, suspicion and envy were prevalent among the contractors. Some of the female contractors were seen as favoured by their managers because of their enthusiasm for the social aspects of the job. One girl, Eun-Keong, was in particular singled out by her team leader: 'She is really a good team member. She never complains about work and has good communication skills.'

The girls were given extra privileges, such as free lunches. And this special treatment, both material and social, was done at the expense of other male contractors, who in some cases were left to work on the girls' assignments. This was felt as another unfair pressure on the male contractors: 'You know it is not easy, my team leader always scolds me and say I do not work hard enough and that Eun-Keong is a good role model (Mobom) - but I think he just likes her better.'

During some of the social gatherings, the fragmentation of the department into smaller groups resulted in physical conflicts between the overly stressed, young male contractors. On one occasion there was a major disagreement between a male newcomer and one of his sonbaes after the female employee Eun-Keong had complained about lack of respect from the male newcomer. Conflicts like these within the group of contractors were seen by the full-time employees as a direct consequence of, on the one hand, the new ideologies of competition and, on the other hand, the conflicting local management strategies. Some employees even confronted their superiors with these accusations. At one social gathering a fight developed between an elderly employee and his team leader. The employee had been drinking too much and showed his dissatisfaction by hitting the team leader with a bottle. 


\section{Joint Efforts for Restoration of a Social Order}

Eventually an almost impossible conflict situation developed in the department, which left all the employees exhausted. Instead of being a healthy and productive unit with good collective results based on individual competition - as advocated by HQ - the department's work started to deteriorate. The situation was characterized by power struggles and social disputes which decreased productivity and jeopardized the possibility of promotion for the managers. It also led to an even higher staff turnover and most employees expressed the wish to be relocated to another department as soon as possible. Even though much time was still devoted to sustaining the group coherence through ideals of the harmonious family, most informants described the unit as a socially fragmented and disharmonious workplace.

By and large, the team leaders and employees made a concerted effort to try to overcome the various conflicts and mutual distrust by scaling up the processes of social regularization. One example of this was the gathering of almost all employees at the wedding ceremony of one of previously mentioned 'favoured' girls, Eun-Keong. It seemed an almost symbolic act of reconciliation, after the recent physical conflicts, to see the erstwhile combatants walking around arm in arm and conversing politely about the dinner reception - or to see the obstinate employee and his team leader shaking hands. According to some functionalist writers, situations like this can be explained as a simple Korean cultural mechanism of group loyalty first and foremost (Vogel 1979; Hofstede and Bond 1988). However, it should also be recognized that at that time all the employees were hoping to be promoted and 'job rotated' away from the branch. (Others, the 'temps' and contractors, could only hope to leave the company if another job became available - an objective that had become even less likely due to the decreased productivity level.) In any event, this example demonstrates that real and strenuous efforts were made by all parties to uphold and embody the ideal of a shared Korean culture - the idea of being a harmonious family despite of (or specifically because of ) the many social disputes.

To sum up, due to the recent shift in corporate ideology, and the effect of the different local interpretations and individual strategies of promotion, recognition and resources, the harmonious balance of cooperation was constantly being challenged. This led to a situation characterized by continuous processes of regularization - thereby laying the seeds for further social disintegration within the 'family'. All in all, there was a 
decline in efficiency and financial results and a lack of social coherence in terms of retaining employees and creating a harmonious working environment. This was the result of a corporate strategy aimed, on the one hand, at introducing a more Western and individually oriented managerial style in order to be able to meet competition from other companies and demands from the IMF, and, on the other hand, ongoing, heightened demands to create a strong 'corporate culture' based on supposedly unique Korean values.

\section{Conclusion}

In this article we have argued that the social harmony of the Korean working group should not be considered as a static or natural trait of Korean organizational life. On the contrary, in our case study harmony and coherence continuously had to be maintained in the social interaction and were often undermined by individual or group-based strategies for acquiring resources or recognition at the expense of other members of the 'family'. This, of course, was partly initiated by the confusion rooted in the introduction of a new Western management style.

Through the company motto, AC Card formulated an ideal of integrating collectivity and individual competition in a harmonious way. Subsequently, the ambiguity of this message was utilized strategically by the management of the Shinchon branch. The local managers interpreted the link between collective solidarity and individual competition in such a way that all subordinates were made accountable for results, though the benefits accrued primarily to the managers themselves. To regain workplace solidarity, in order to boost the managers' chances of promotion, a large number of social gatherings were initiated. Even though these arrangements created some sense of mutual belonging, they also became the arena of conflict between different groups and employees, and between managers and subordinates - and finally they harmed performance.

The expressed idea of a harmonious family, thus, did not exist per se, but was only the result of hard work, by managers and employees, manoeuvring between two differently defined ideals: the so-called 'American way' and the 'Korean way'. Hence, the official ideal of the harmonious family became not only the ultimate goal to strive for but also the strategic means to increase productivity in a working group which, apart from a few local managers, did not stand to gain personally from the results of their work. 
It is recognized that the findings reported in this article are based on a single piece of ethnographic fieldwork and, as such, they do not aim at formal generalization or comparison. In addition, the social dynamics described may be characterized as an extreme case due to the transitional phase of the organization under study. However, the dynamics of daily interaction and negotiation of ideals and values for acquiring resources and recognition may to some extent be extrapolated as a general feature, and important conclusions relating to Asian corporate organizations can therefore be drawn. Furthermore, other examples of similar studies of social processes in Asian organizations point in the same direction (Kondo 1990; Janelli 1996). Janelli's (1996) study of a large Korean corporation showed that the understanding of harmony as an integral part of the managerial ideology was linked to national causes and thereby used and interpreted by the leaders for material purposes.

Even a cursory review of the literature of Asian organizations will reveal that the social dynamics of the workplace have tended to be neglected and even obscured by the essentialization of 'Asian culture' as a collectively supported social harmony, in opposition to Western individual competitiveness (Hofstede 1991; Hofstede and Bond 1988). Furthermore, it has often been claimed that the corporate coherence and integration 'naturally' will lead to social solidarity among the organizational members (Vogel 1979; Ouchi 1982). This essentialization of culture - and particularly Asian culture - can easily be seized upon as the main explanatory factor for all social and corporate action (e.g. Herzfeld 2005). In the case presented it even became the driving force for local managerial strategies. There is a need for further investigation into how ideals connected to Asian workplaces, by scholars and managers, are formed, maintained and interpreted through social action and thereby also gain significant meaning for social actions (Holy and Stuchlik 1983; Moeran 1984; Tsukaguchi-le Grand 1991).

It is necessary to accept that organizational and national cultural traits are not static but continually reinterpreted. This highlights the need for a deeper understanding of the structured collective and individual application and interpretation of different management ideologies in organizations. In addition, we need to know how this affects the ongoing social processes of regularization as well as situational adjustment - both of which create a social order and at the same time adjust it to the inherent needs. This requires further investigation before a more definitive linkage between East Asian culture and financial results can be postulated. 
These suggestions are made in the knowledge that there is a general need for further research on Asian organizations from a process-oriented perspective - as carried out by authors like Kondo (1990), Janelli (1996) and Moeran (2005). The analytical framework of this article has suggested that we should view culture as a dynamic, continuously negotiated social structure (Barth 1966; Bourdieu 1990). Scholars in the field of Asian studies could explore this theme through further studies on the influence of cultural norms and values on organizational behaviour and productivity. In this article an interdisciplinary approach combining anthropology and organization studies was applied to gain an understanding of the social organization within a Korean corporation. However, other perspectives within the field of social studies might provide additional or complementary information on the organization and management of working life in Asian organizations.

Charlotte Jonasson is a Teaching Assistant at Aarhus University, Denmark. Email:etnocj@hum.au.dk

Jakob Lauring is Assistant Professor at the Aarhus School of Business, Department of Management and International Business. Email: Jala@asb.dk.

\section{NOTES}

1 The cultural discourse of East Asian organization had already been challenged during the 1980s and 1990s by scholars within the social sciences (Janelli 1996; Kondo 1990).

2 As some writers mention (Rhee and Chang 2002; Patterson 2002), it is remarkable that the previous conclusions on Korean 'culture' were rejected so suddenly.

3 Song and Meek (1998) argue that managerial values in Korea, through the sahoon are articulated in a way that corresponds to the national core values of harmony, unity, collectivity and vertical social relations.

4 It has however been noted by some that the sahoon often changes without any real implementation and therefore is left unnoticed by many employees (Kim 1999; Jang and Chung 1997).

5 Officialization is a social process whereby certain statements, stances or ideas become institutionalized as the 'right', official and influential norms, stances or values of society. The main argument follows that these statements are also used strategically to legitimize individual or group actions and efforts to obtain different resources (Bourdieu 1977).

6 Such social gatherings for drinking have by many been described as typical realizations of - and efforts to uphold the 'Asian value' of collectivity and group harmony (Vogel 1979; Ouchi 1982). However, this view on social gatherings has also been critiqued for conceptualizing the contexts as 'black box' situations and not as social interactions in themselves and a part of a social context (Ben-Ari 2002). 


\section{REFERENCES}

Adler, N. J. 1997. International Dimensions of Organisational Behaviour. Cincinnati: South Western Publishing.

Ames, R. T. 1993. The Art of Rulership: A Study in Ancient Chinese Political Thought. New York: University of Hawaii Press.

Bar-Tal, D. 1990. Group Beliefs: A Conception for Analyzing Group Structure, Processes, and Behavior. New York: Springer Verlag.

Barth, F. 1966. Models of Social Organization. Glasgow: The University Press.

- 1989. 'The Analysis of Culture in Complex Societies'. Ethnos 54, Vols III-IV.

- 1993. Balinese Worlds. Chicago: University of Chicago Press.

Ben-Ari, E. 2002. 'At the Interstices: Drinking, Management and Temporary Groups in a Local Japanese Organization.' In J. Hendry (ed.), Japanese Organization Japan at Play - the Ludic and Logic of Power. New York: Routledge.

Bernard, R. H. 1995. Research Methods in Anthropology, Qualitative and Quantitative Approaches. Thousand Oaks, CA: Sage.

Bourdieu, P. 1977. Outline of a Theory of Practice. Cambridge: Cambridge University Press.

- 1990. The Logic of Practice. New York: Polity Press.

- 2004. Distinction: A Social Critique of the Judgement of Taste. London: Routledge.

Chang, N. J. 1999. 'Behavioral Patterns of Koreans.'. In H. Lee (ed.), Comparative Management: Readings and Cases. Seoul: Yonsei University Press.

Chung, M.-H. and S. Jang 1997. Discursive Contradiction of Tradition and Modernity in Korean Management Practices: A Case Study of Samsung's New Management. London: Sage.

Deal, T. E. and A. A. Kennedy 1983. Corporate Cultures: The Rites and Rituals of Corporate Life. Reading: Addison-Wesley.

Dewalt, K. M., B. R. Dewalt et al. 1998. 'Participant Observation.' In R. Bernard (ed.), Handbook of Methods in Cultural Anthropology. Walnut Creek: AltaMira.

Edgren, L. D. 1990. 'The "Commando" Model: A Way to Gather and Interpret Cultural Data in the Swedish Public Sector.' In B. A. Turner (ed.), Organizational Symbolism. Berlin/ New York: Walter de Gruyter.

Fang, T. 2003. 'A critique of Hofstede's Fifth National Culture Dimension.' International Journal of Cross Cultural Management 3 (3): 347-68.

Flyvbjerg, B. 2001. Making Social Science Matter: Why Social Inquiry Fails and How It Can Succeed Again. Cambridge: Cambridge University Press.

Geertz, C. 1973. The Interpretation of Cultures: Selected Essays. New York: Basic Books.

Gudykunst, W. B. 2004. Bridging Differences: Effective Intergroup Communication. London: Sage Publications.

Hahm, P. C. 1986. Korean Jurisprudence, Politics and Culture. Seoul: Yonsei University Press.

Hall, D. L. and R. T. Ames 1987. Thinking through Confucius. Albany: State University of New York Press.

Herzfeld, M. 2005. Cultural Intimacy, Social Poetics in the Nation-State. New York: Routledge.

Hofstede, G. 1991. Cultures and Organizations: Software of the Mind. London: McGrawHill.

Hofstede, G and M. Bond 1988. 'The Confucius Connection: From Cultural Roots to Economic Growth.' Organizational Dynamics 16 (4): 5-21.

Holy, L. and M. Stuchlik 1983. Actions, Norms and Representations: Foundations of Anthropological Inquiry. Cambridge: Cambridge University Press.

Jandt, F. E. 2001. Intercultural Communication. Thousands Oaks, CA: Sage. 
Janelli, R. L. 1996. Making Capitalism: The Social and Cultural Construction of a South Korean Conglomerate. Stanford: Stanford University Press.

Janis, I. L. 1982. Groupthink: Psychological Studies of Policy Decisions and Fiascos. Boston: Houghton Mifflin.

Jonasson, C. and J. Lauring 2005. Konstruktionen af 'ingroup'-strukturer i en koreansk virksomhed: Skabelsen af den harmoniske familie? Working Paper, Department of Management. Aarhus School of Business.

Kim, C. S. 1999. The Culture of Korean Industry. Seoul: Yonsei University Press.

Kim, U., G. Helgesen, G., \& Ahn, B. M 2002. 'Democracy, Trust, and Political Efficacy: Comparative Analysis of Danish and Korean Political Culture.' Applied Psychology: An International Review 51 (2): 318-53.

King, N. and N. Anderson 1990. Innovation in Working Groups: Innovation and Creativity at Work. New York: Wiley.

Kondo, D. 1990. Crafting Selves Power, Gender and Discourses of Identity in a Japanese Workplace. Chicago: University of Chicago Press.

Lee, B. H. 2003. 'Globalization and Industrial Relations in Korea.' Korea Journal 43 (1): 261-88.

Lee, H. J. 1989. 'Managerial Characteristics of Korean Firms.' In H. C. Chung, K. H. Lee and H. J. Lee (eds), Korean Managerial Dynamics. New York: Praeger.

Lee, S. H. 1998. 'Crisis in Korea and the IMF Control.' In E. M. Kim (ed.), The Four Asian Tigers: Economic Development and the Global Political Economy. New York: Academic Press.

Lett, D. P. 1998. The Making of South Korea's 'New' Urban Middle Class. Cambridge, MA: Harvard University Press.

Marcus, G. E. 1995. Ethnography in/of the World System: The Emergence of MultiSited Ethnography. In G. Marcus (Ed.), Ethnography through Thick and Thin. Princeton: Princeton University Press.

McMichael, P. 2002. Development and Social Change: a Global Perspective. London: Pine Forge.

Miles, M. and M. Huberman 1994. Qualitative Data Analysis. London: Sage.

Moeran, B. 1984. 'Individual, Group and Seishin: Japans Internal Cultural Debate.' Man 19 (2): 252-66.

- 2005. The Business of Ethnography. New York: Berg.

Moore, S. F. 1978. Law as Process. London: Routledge and Kegan Paul.

- 1994. 'The Ethnography of the Present and the Analysis of Process.' In R. Borofsky (ed.), Assessing Cultural Anthropology. New York: McGraw-Hill.

Oh, T. K. and E. Kim 2002. 'The Impact of Confucianism on East Asian Business Enterprises.' In R. Chang (ed.), Korean Business and Management: The Reality and the Vision. Seoul: Holym.

Ouchi, W. 1982. Theory Z: How American Business Can Meet the Japanese Challenge. New York: Avon.

Pascale, R. T. and A. G. Athos 1981. The Art of Japanese Management: Applications for American Executives. New York: Simon \& Schuster.

Patterson, D. P. 2002. 'Asian Management Styles: the Evidence from Korea.' In R. Chang (ed.), Korean Business and Management the Reality and the Vision. Seoul: Hollym.

Peters, T. J. and R. H. Waterman 2004. In Search of Excellence: Lessons from America's Best-run Companies. London: Profile.

Rhee and Chang 2002. 'Introduction' in R. Chang (ed.), Korean Business and Management: the Reality and the Vision. Seoul: Hollym.

Rowler, C., T. W. Sohn, T.W., \& Bae, J. 2002. Managing Korean Business: Organization, Culture, Human Resources and Change. London: Frank Cass. 
Song, Y. H. and C. B. Meek 1998. 'The Impact of Culture on the Management Values and Beliefs of Korean Firms.' Journal of Comparative International Management 1 (1): 1-19.

Spradley, J. P. 1980. Participant Observation. New York: Holt Rinehart \& Winston.

Triandis, H. C. 1995. Individualism and Collectivism. Boulder, CO: Westview Press.

Tsukaguchi-le Grand, T. 1991. Rethinking the 'Japanese Collectivism': Nihonjinron as Ideology Perspectives on Japan and Korea. Second Nordic Symposium on Japanese and Korean studies, Copenhagen: NIAS.

Turner, V. 1969. The Ritual Process: Structure and Anti-Structure. Chicago: Aldine.

Ungeson, G. R., R. M. Steers, R.M., \& Park, S.H. 1999. Management and the New Confucianism. Seoul: Yonsei University Press.

Van Gennep, A. 1990. The Rites of Passage. Chicago: The University of Chicago Press.

Vogel, E. F. 1979. Japan as Number One: Lessons for America. Cambridge, MA: Harvard University Press.

Weick, K. E. 1979. The Social Psychology of Organizing. London: Addison-Wesley.

- 1993. 'Sense Making in Organizations: Small Structures with Large Consequences.' In K. Murnighan (ed.), Social Psychology in Organizations. Engelwood Cliffs: Prentice Hall. 